\title{
WHO/UNDP: THE SPECIAL PROGRAMME FOR RESEARCH AND TRAINING IN TROPICAL DISEASES
}

\section{Reports of Progress in 1976 and 1977}

Following the issue, to all interested applicants, of Volume I (Introduction, The Diseases, the Research and Training Needs; Malaria, Schistosomiasis, Filariasis, Trypanosomiasis, Leishmaniasis and Leprosy), Volume II (Epidemiology, Biomedical Research, Vector Biology, Socio-economic Considerations, Training and Institution Strengthening, Prior Scientific Recommendations, Programme Management), and a separate Inventory of African Research Institutions, a further loose-leaf volume has now been produced, which includes the following:

Report of the THELEP Screening Committee, Geneva, 14-15 December 1976, Report of the Third IMMLEP Scientific Working Group Meeting, 21-25 February 1977, Report of the First Meeting of the THELEP Scientific Working Group, Geneva, 15-29 April 1977.

A Report of special importance for leprosy is that of the First Meeting of THELEP, where pages 8 and 9 deal with drug regimens to be tested, and Appendix 5.13 and 5.14 with the management of reversal reactions and of erythema nodosum leprosum.

We continue to draw attention to the development and progress of this momentous Special Programme for obvious reasons, and take this opportunity of reminding readers of Leprosy Review that by writing 
formally to Hilary Boardman, Secretary, Special Programme for Research and Training in Tropical Diseases, WHO, 1211 Geneva 27, Switzerland, bona fide applicants may obtain documentation on the Programme, and also have a regular Newsletter posted to them.

A. C. McDOUGALL 